\title{
Primary sclerosing cholangitis as an intractable disease
}

\author{
Sumihito Tamura, Yasuhiko Sugawara*, Norihiro Kokudo \\ Artificial Organ and Transplantation Division, Department of Surgery, Graduate School of Medicine, The University of Tokyo, \\ Tokyo, Japan.
}

\begin{abstract}
Summary Primary sclerosing cholangitis (PSC) is a chronic cholestatic liver disease of unknown origin which eventually results in liver cirrhosis. The disease is reported to be more common among the Western population than in the Asian population. Asian experience remains limited. Diagnosis and treatment standards in the Far East have largely followed those in the West, including liver transplantation. Unlike in the West, however, recent reports from Japan have presented with a higher recurrence rate of PSC after liver transplantation, suggesting the intractable nature of the disease even after the replacement of the entire affected organ.
\end{abstract}

Keywords: Primary sclerosing cholangitis (PSC), living donor liver transplantation (LDLT), deceased donor liver transplantation (DDLT), Japan

\section{Introduction}

Primary sclerosing cholangitis (PSC) is a chronic cholestatic liver disease, characterized by inflammatory and fibrotic bile duct lesions forming multiple strictures and dilatations of the intra- and extrahepatic bile ducts (1-3). The disease is more common in men than women, and among Caucasians and Northern Europeans, than in Southern Europeans, Asians, or Africans $(4,5)$.

Criteria for diagnosis are; cholangiographic findings of multifocal strictures and beading of the intraand/ or extra-hepatic bile ducts, compatible biochemical abnormalities, and exclusion of secondary causes $(1,4,6)$. PSC is closely linked to inflammatory bowel disease (IBD), and some cases come to medical attention when patients with IBD are screened for liver disease (7). Genetic disposition and disordered immune regulation is considered to have a role in PSC. A recent report suggested that first-degree relatives and siblings are associated with a PSC prevalence approximately

*Address correspondence to:

Dr. Yasuhiko Sugawara, Artificial Organ and Transplantation Division, Department of Surgery, Graduate School of Medicine, The University of Tokyo, 7-3-1 Hongo, Bunkyo-ku, Tokyo 113-8655, Japan.

E-mail: yasusuga-tky@umin.ac.jp
100 -fold that of nonrelatives (8). However, specific mechanisms remain un-clarified to date (1).

Gradual progression of cholestasis results in end-stage liver disease (ESLD). Ursodeoxycholic acid administration, with or without the use of immunosuppressive agents, seems to have a moderate clinical effect on liver function tests, but it is not clear whether there is a beneficial effect on delaying the progression of the disease and improving the overall survival rate $(4,9)$. Effective medical treatment remains a matter of debate.

\section{PSC and liver transplantation}

Liver transplantation is the optimal treatment for patients with PSC presenting with ESLD and associated complications, such as severe manifestations of portal hypertension (4). The short-term outcome has been excellent. The impact of a recurrence on long-term survival has been a concern but was not significant in deceased donor liver transplantation (DDLT) based on Western experience (10).

In Asia, especially in the Far East, however, organs from deceased donors remain extremely scarce. LDLT has been accepted with enthusiasm and its indications have been extended to adult recipients $(11,12)$.

Despite technical difficulties and the ethical dilemma, well planned donor selection protocol and technical innovations have paved the way for 
advancement with satisfactory results $(13,14)$. LDLT for adult recipients has become standard practice in the region for various indications including ESLD due to PSC.

\section{DDLT and PSC}

Although a higher rate of re-transplantation has been reported, PSC is considered a good indication for DDLT with an excellent 5-year graft survival rate of approximately $80 \%$. Evidence of recurrence has been suggested in earlier experience $(15,16)$, and is currently an established concept (17). Recurrence of PSC after DDLT has been reported at rates between $1 \%$ to $33 \%$, depending on the diagnostic criteria and follow-up duration (4).

Graziadei and colleagues proposed combined cholangiographic and hepatic histologic criteria with strict exclusion criteria (cases with ABO incompatibility between donor and recipient, nonanastomotic strictures before posttransplantation day 90, anastomotic strictures alone, hepatic artery complications, or ductopenic rejection were excluded) and reported that PSC recurs after DDLT in $20 \%$ of cases with typical radiologic manifestations found within a year, and histologic presentation within 3 years after DDLT (18).

Factors affecting recurrence have been extensively studied in the Western literature. An earlier retrospective study suggested that the presence of an intact colon before transplantation was significantly associated with recurrence (17). Other studies identified different factors as risk: recipient-donor gender mismatch (19), use of OKT3 or steroid resistant rejections $(20,21)$, persistent ulcerative colitis after transplantation (22), human leukocyte antigen DRB1*08 (HLADRB1*08) (23). A most recent large series with a longer follow up period supports the findings that colectomy remains a significant risk factor, and further, use of extended donor criteria may also be a significant risk factor (24).

\section{Recurrence of PSC in LDLT}

A case suspected of recurrent PSC following LDLT was first reported by Kita et al. (25). Since then, there have been sporadic case reports of LDLT for PSC from living related donors (26-34) (Figure 1). However, follow-up periods were less than 2 years in most case reports, and recurrence was not reported.

Aside from these case reports, LDLT for PSC can be sporadically identified among moderate to large registries worldwide (35-38). From Korea, Moon et al. (35) reported 2 cases among 580 recipients. From Japan, Soejima et al. (36) also reported 2 cases of LDLT for PSC in their series of 52 LDLTs. Both, however, lacked a specific description of the long term outcome. The largest PSC registry analysis by Maheshwari et al. (38) reported the outcome of 3,309

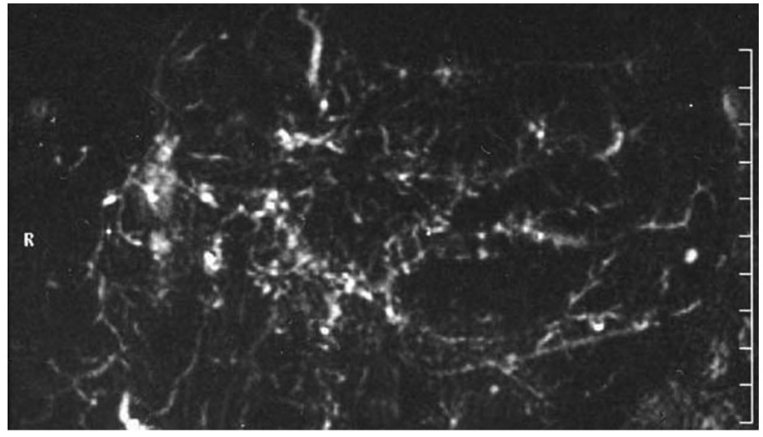

Figure 1. Representative radiologic image of Recurrent Primary Sclerosing Cholangitis following living donor liver transplantation. Drip infusion computed tomography cholangiography obtained from a typical recurrent case. Note the multifocal strictures and beading of the bile ducts within the engrafted partial liver.

patients who underwent liver transplantation, among whom 69 cases were LDLT. Only 10 cases presented with a follow-up period longer than a year.

An explanation for this lack of information on the long-term outcome of LDLT for PSC, especially regarding recurrence, may be due to the rare incidence of PSC in the Far East where LDLT is far more common than DDLT.

\section{PSC in Japan and LDLT}

Report on the epidemiology of PSC in Asian countries remains scarce. Currently, large registry analysis or nationwide survey study results are only available from Japan (Figures 2 and 3).

A recent nationwide survey from Japan including 391 patients with PSC with a median follow up period of over five years presented that the estimated median survival of all patients was 13.1 years, with a 5-year survival rate of $74.5 \%$. Thirty-eight patients underwent liver transplantation with a 5-year survival rate of $92.0 \%$. Cholangiocarcinoma was found in $14(3.6 \%)$ patients. Prevalence of IBD was 32\%. Interestingly, authors' pointed out two distinctive features recognized among Japanese patients. First, two peaks in age distribution were demonstrated (in the twenties and in the sixties) an uncommon distribution not reported in the Western series. Second, while the presence of IBD was limited to $37 \%, 7.2 \%$ of patients, mainly those older than 50 years of age, experienced autoimmune pancreatitis (39-41).

Earlier registry analysis including 66 patients who underwent LDLT for PSC has raised a concern on the impact of recurrence calling for study with well defined diagnostic criteria and a longer follow up period (42). Since then, two single center case series of LDLT for PSC have been published from high volume centers $(43,44)$.

The Tokyo group described the outcome of 9 adult LDLT cases, of which 8 were living-related. The 
median follow-up period was 3.5 years after LDLT. The five-year patient survival rate was $90 \%$. According to Graziadei's criteria (18), however, recurrent PSC was diagnosed in four patients. The rate of freedom from recurrent PSC at 5 years was $49 \%$. The mean time to recurrence was 3.3 years. When limited to biologically related donor-recipient cases, recurrent PSC was diagnosed in $50 \%$ of cases. None of the patients presented with the HLA haplotypes associated with a higher susceptibility for developing PSC in the Caucasian population (43).

The Kyoto group reported 28 patients with PSC who underwent LDLT. Among the 22 patients who

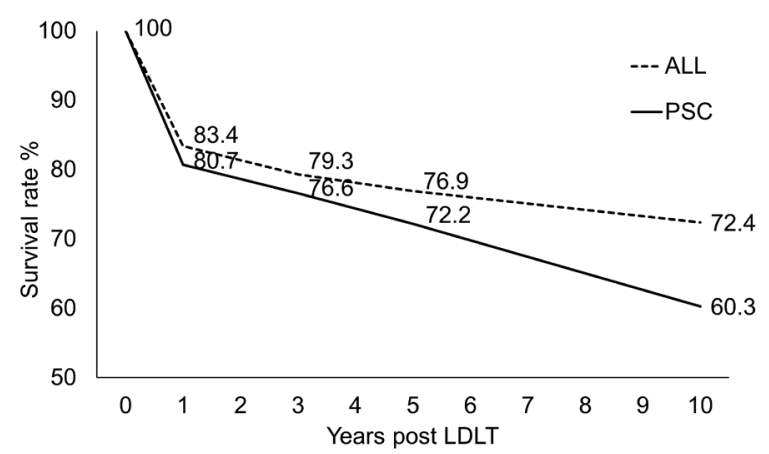

Figure 2. Outcome of living donor liver transplantation in Japan. Data obtained from the annual registry report provided by the Japanese Liver Transplantation Society (ref. 46). Abbreviations: ALL, all national cases combined; PSC, primary sclerosing cholangitis; LDLT, living donor liver transplantation. survived for more than a year, $13(59 \%)$ presented with PSC recurrence with a mean follow-up period of 31 months, 5 of whom died or required re-transplantation due to graft failure. The HLA haplotypes that may affect recurrence of the hepatic condition remain unclear, although HLA-DR15 is positively associated with ulcerative colitis. The group concluded that unlike $\mathrm{PBC}$, the recurrence of PSC adversely affects the outcome in LDLT (44).

Finally, based on the above two reports, a nationwide survey was conducted collecting the data of 132 patients from 29 centers in Japan. Fifty-three (40\%) had IBD, and 4 (3\%) had cholangiocarcinoma. After excluding patients not undergoing primary standard LDLT, and further, excluding ABO-incompatible cases, those complicated with hepatic artery thrombosis and ductopenic rejection, 96 remained for analysis. Recurrence was diagnosed in 26 patients (27\%) after transplantation. Recurrence-free survival was $57 \%$ at 5 years after LDLT and graft loss rate was $69 \%$ among those with recurrence compared to $23 \%$ among those without. Multivariate analysis revealed that high MELD scores, first-degree-relative donors, postoperative CMV infection, and early biliary anastomotic complications were significant risk factors for recurrence (45).

\section{Conclusion}

Indeed, presenting with a high rate of recurrence after replacement of the entire affected organ, PSC

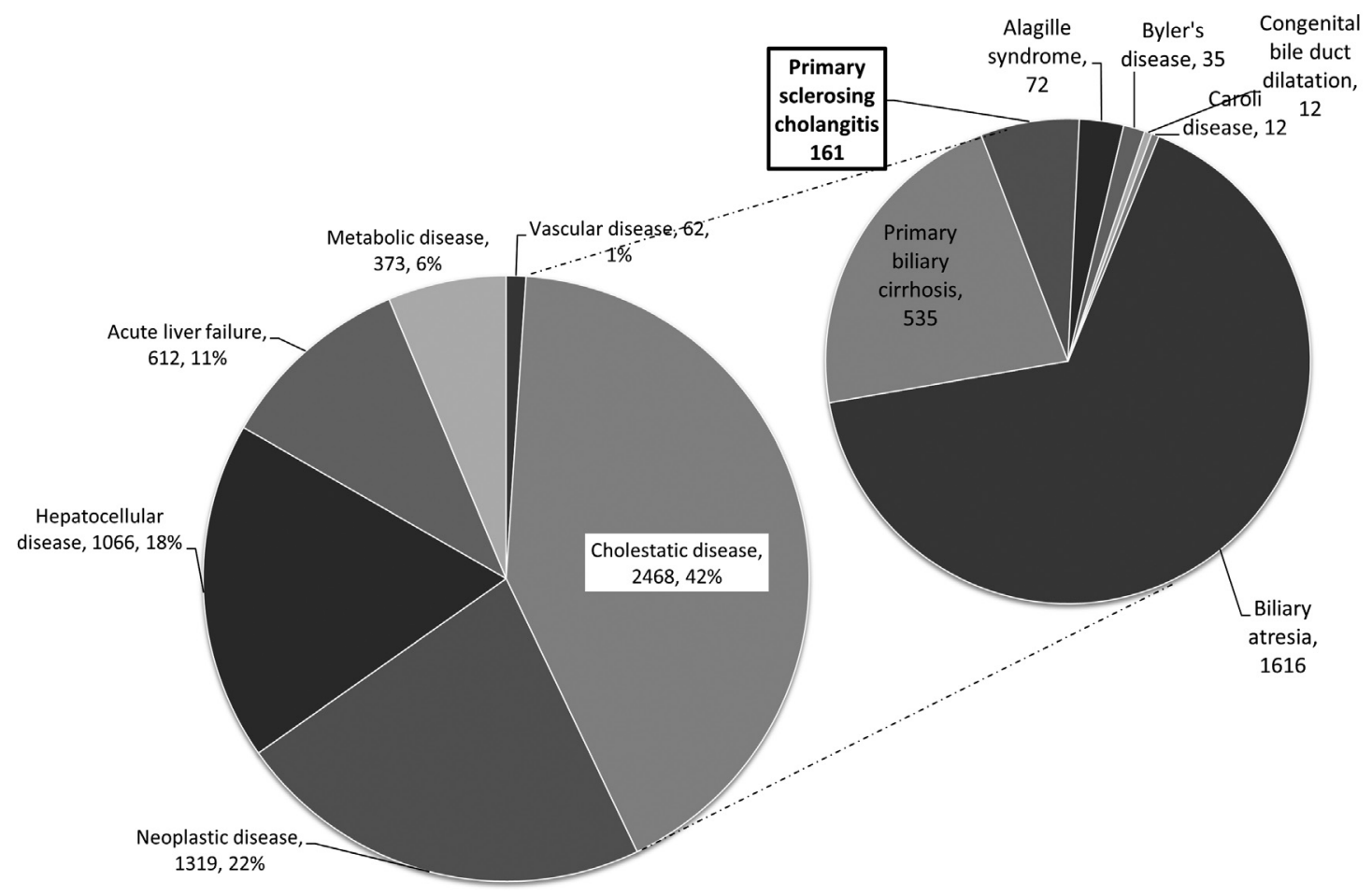

Figure 3. Indication for living donor liver transplantation in Japan. Data obtained from the annual registry report provided by the Japanese Liver Transplantation Society (ref. 46). Primary scerosing cholangits remains a rare indication in Japan. 
encountered in the LDLT setting seems like an intractable entity. In addition, much remains unknown about the nature of PSC in the Far East where LDLT is predominantly performed in place of DDLT as compared to the West.

Whether the high rate of recurrence following transplantation in Japan may be attributed to the unrecognized genetic background, or to the characteristic organ source found in the region that is often from a biologically related living donor, remains to be elucidated.

\section{Acknowledgements}

This work was supported by a Grant-in-aid for Scientific Research from the Ministry of Education, Culture, Sports, Science and Technology of Japan and Grants-in-aid for Research on HIV/AIDS and Research on Measures for Intractable Diseases from the Ministry of Health, Labor and Welfare of Japan.

\section{References}

1. Angulo P, Lindor KD. Primary sclerosing cholangitis. Hepatology. 1999; 30:325-332.

2. Lee YM, Kaplan MM. Primary sclerosing cholangitis. N Engl J Med. 1995; 332:924-933.

3. Portincasa P, Vacca M, Moschetta A, Petruzzelli M, Palasciano G, van Erpecum KJ, van Berge-Henegouwen GP. Primary sclerosing cholangitis: Updates in diagnosis and therapy. World J Gastroenterol. 2005; 11:7-16.

4. LaRusso NF, Shneider BL, Black D, Gores GJ, James SP, Doo E, Hoofnagle JH. Primary sclerosing cholangitis: Summary of a workshop. Hepatology. 2006; 44:746-764.

5. Bjøro K, Friman S, Höckerstedt K, Kirkegaard P, Keiding S, Schrumpf E, Olausson M, Oksanen A, Isoniemi H, Hjortrup A, Bergan A, Ericzon BG. Liver transplantation in the Nordic countries, 1982-1998: Changes of indications and improving results. Scand J Gastroenterol. 1999; 34:714-722.

6. Chapman RW, Arborgh BA, Rhodes JM, Summerfield JA, Dick R, Scheuer PJ, Sherlock S. Primary sclerosing cholangitis: a review of its clinical features, cholangiography, and hepatic histology. Gut. 1980; 21:870-877.

7. MacFaul GR, Chapman RW. Sclerosing cholangitis. Curr Opin Gastroenterol. 2005; 21:348-353.

8. Bergquist A, Lindberg G, Saarinen S, Broomé U. Increased prevalence of primary sclerosing cholangitis among first-degree relatives. J Hepatol. 2005; 42:252-256.

9. Mitchell SA, Bansi DS, Hunt N, Von Bergmann K, Fleming KA, Chapman RW. A preliminary trial of high-dose ursodeoxycholic acid in primary sclerosing cholangitis. Gastroenterology. 2001; 121:900-907.

10. Faust TW. Recurrent primary biliary cirrhosis, primary sclerosing cholangitis, and autoimmune hepatitis after transplantation. Liver Transpl. 2001; 7:S99-108.

11. Sugawara Y, Makuuchi M. Technical advances in livingrelated liver transplantation. J Hepatobiliary Pancreat Surg. 1999; 6:245-253.
12. Hashikura Y, Makuuchi M, Kawasaki S, Matsunami H, Ikegami T, Nakazawa Y, Kiyosawa K, Ichida T. Successful living-related partial liver transplantation to an adult patient. Lancet. 1994; 343:1233-1234.

13. Yamashiki N, Sugawara Y, Tamura S, Kaneko J, Nojiri K, Omata M, Makuuchi M. Selection of livertransplant candidates for adult-to-adult living donor liver transplantation as the only surgical option for end-stage liver disease. Liver Transpl. 2006; 12:1077-1083.

14. Tamura S, Sugawara Y, Kokudo N. Donor evaluation and hepatectomy for living-donor liver transplantation. J Hepatobiliary Pancreat Surg. 2008; 15:79-91.

15. Harrison RF, Davies MH, Neuberger JM, Hubscher SG. Fibrous and obliterative cholangitis in liver allografts: Evidence of recurrent primary sclerosing cholangitis? Hepatology. 1994; 20:356-361.

16. Sheng R, Campbell WL, Zajko AB, Baron RL. Cholangiographic features of biliary strictures after liver transplantation for primary sclerosing cholangitis: Evidence of recurrent disease. AJR Am J Roentgenol. 1996; 166: 1109-1113.

17. Vera A, Moledina S, Gunson B, Hubscher S, Mirza D, Olliff S, Neuberger J. Risk factors for recurrence of primary sclerosing cholangitis of liver allograft. Lancet. 2002; 360:1943-1944.

18. Graziadei IW, Wiesner RH, Batts KP, Marotta PJ, LaRusso NF, Porayko MK, Hay JE, Gores GJ, Charlton MR, Ludwig J, Poterucha JJ, Steers JL, Krom RA. Recurrence of primary sclerosing cholangitis following liver transplantation. Hepatology. 1999; 29:1050-1056.

19. Khettry U, Keaveny A, Goldar-Najafi A, Lewis WD, Pomfret EA, Pomposelli JJ, Jenkins RL, Gordon FD. Liver transplantation for primary sclerosing cholangitis: A long-term clinicopathologic study. Hum Pathol. 2003; 34:1127-1136.

20. Kugelmas M, Spiegelman P, Osgood MJ, Young DA, Trotter JF, Steinberg T, Wachs ME, Bak T, Kam I, Everson GT. Different immunosuppressive regimens and recurrence of primary sclerosing cholangitis after liver transplantation. Liver Transpl. 2003; 9:727-732.

21. Brandsaeter B, Schrumpf E, Bentdal O, Brabrand K, Smith HJ, Abildgaard A, Clausen OP, Bjoro K. Recurrent primary sclerosing cholangitis after liver transplantation: A magnetic resonance cholangiography study with analyses of predictive factors. Liver Transpl. 2005; 11:1361-1369.

22. Cholongitas E, Shusang V, Papatheodoridis GV, Marelli L, Manousou P, Rolando N, Patch D, Rolles K, Davidson $\mathrm{B}$, Burroughs AK. Risk factors for recurrence of primary sclerosing cholangitis after liver transplantation. Liver Transpl. 2008; 14:138-143.

23. Alexander J, Lord JD, Yeh MM, Cuevas C, Bakthavatsalam R, Kowdley KV. Risk factors for recurrence of primary sclerosing cholangitis after liver transplantation. Liver Transpl. 2008; 14:245-251.

24. Alabraba E, Nightingale P, Gunson B, Hubscher S, Olliff S, Mirza D, Neuberger J. A re-evaluation of the risk factors for the recurrence of primary sclerosing cholangitis in liver allografts. Liver Transpl. 2009; 15:330-340

25. Kita Y, Lake JR, Ferrell LD, et al. Possible recurrence of primary sclerosing cholangitis following living-related liver transplantation: Report of a case. Transplant Proc. 1998; 30:3321-3323.

26. Wachs ME, Bak TE, Karrer FM, Everson GT, Shrestha R, 
Trouillot TE, Mandell MS, Steinberg TG, Kam I. Adult living donor liver transplantation using a right hepatic lobe. Transplantation. 1998; 66:1313-1316.

27. Kaibori M, Uemoto S, Fujita S, Inomata Y, Egawa H, Asonuma K, Kiuchi T, Hayashi M, Nakamura M, Tanaka K. Native hepatectomy after auxiliary partial orthotopic liver transplantation. Transplant Int. 1999; 12:383-386.

28. Ikegami T, Nishizaki T, Yanaga K, Kakizoe S, Nomoto K, Ohta R, Minagawa R, Sugimachi K. Living-related auxiliary partial orthotopic liver transplantation for primary sclerosing chonangitis - subsequent removal of the native liver. Hepatogastroenterology. 1999; 46:2951-2954.

29. Nakamura M, Fuchinoue S, Nakajima I, Kitajima K, Tojimbara T, Takasaki K, Shiraga H, Ito K, Tanaka $\mathrm{K}$, Agishi T. Three cases of sequential liver-kidney transplantation from living-related donors. Nephrol Dial Transplant. 2001; 16:166-168.

30. Varotti G, Gondolesi GE, Roayaie S, Suriawinata A, Soltys K, Fishbein TM, Schwartz ME, Miller C. Combined adult-to-adult living donor right lobe liver transplantation and pancreatoduodenectomy for distal bile duct adenocarcinoma in a patient with primary sclerosing cholangitis. J Am Coll Surg. 2003; 197:765-769.

31. Akyildiz M, Karasu Z, Cagirgan S, Kilic M, Tokat Y. Rituximab therapy for life-threatening immune hemolytic anemia in a liver tranplant recipient: A case report. Transplant Proc. 2004; 36:1492-1493.

32. Oya H, Sato Y, Yamamoto S, Takeishi T, Kobayashi T, Hatakeyama K. Living related donor liver transplantation for primary sclerosing cholangitis with hepatocellular carcinoma and Crohn's disease: A case report. Transplant Proc. 2004; 36:2297-2298.

33. Jabbour N, Gagandeep S, Mateo R, Sher L, Henderson R, Selby R, Genyk Y. Live donor liver transplantation: Staging hepatectomy in a Jehovah's Witness recipient. J Hepatobiliary Pancreat Surg. 2004; 11:211-214.

34. Heimbach JK, Menon KV, Ishitani MB, Nyberg SL, Jankowski CJ, Lindor KD, Rosen CB. Living donor liver transplantation using a right lobe graft in an adult with situs inversus. Liver Transpl. 2005; 11:111-113.

35. Moon DB, Lee SG. Adult-to-adult living donor liver transplantation at the Asan Medical Center. Yonsei Med J. 2004; 45:1162-1168.

36. Soejima Y, Harada N, Shimada M, Suehiro T, Minagawa R, Hiroshige S, Ninomiya M, Shiotani S, Nishizaki T. Perioperative management and complications in donors related to living-donor liver transplantation. Surgery. 2002; 131:S195-199.

37. Hayashi PH, Forman L, Steinberg T, Bak T, Wachs M, Kugelmas M, Everson GT, Kam I, Trotter JF. Model for End-Stage Liver Disease score does not predict patient or graft survival in living donor liver transplant recipients. Liver Transpl. 2003; 9:737-740.

38. Maheshwari A, Yoo HY, Thuluvath PJ. Long-term outcome of liver transplantation in patients with PSC: A comparative analysis with PBC. Am J Gastroenterol. 2004; 99:538-542.

39. Takikawa H, Manabe T. Primary sclerosing cholangitis in Japan - analysis of 192 cases. J Gastroenterol. 1997; 32:134-137.

40. Takikawa H, Takamori Y, Tanaka A, Kurihara H, Nakanuma Y. Analysis of 388 cases of primary sclerosing cholangitis in Japan: Presence of a subgroup without pancreatic involvement in older patients. Hepatol Res. 2004; 29:153-159.

41. Tanaka A, Takamori Y, Toda G, Ohnishi S, Takikawa H. Outcome and prognostic factors of 391 Japanese patients with primary sclerosing cholangitis. Liver Int. 2008; 28:983-989.

42. Yamagiwa S, Ichida T. Recurrence of primary biliary cirrhosis and primary sclerosing cholangitis after liver transplantation in Japan. Hepatol Res. 2007; 37 (Suppl 3): S449-454.

43. Tamura S, Sugawara Y, Kaneko J, Matsui Y, Togashi J, Makuuchi M. Recurrence of primary sclerosing cholangitis after living donor liver transplantation. Liver Int. 2007; 27:86-94.

44. Haga H, Miyagawa-Hayashino A, Taira K, Morioka D, Egawa H, Takada Y, Manabe T, Uemoto S. Histological recurrence of autoimmune liver diseases after livingdonor liver transplantation. Hepatol Res. 2007; 37(Suppl 3):S463-469.

45. Egawa H, Ueda Y, Ichida T, Teramukai S, Nakanuma Y, Onishi S, Tsubouchi H. Risk factors for recurrence of primary sclerosing cholangitis after living donor liver transplantation in Japanese registry. Am J Transplant. 2011; 11:518-527.

46. The Japanese Liver Transplantation Society. Liver transplantation in Japan - Registry by the Japanese Liver Transplant Society. Japanese Journal of Transplantation 2011; 46:524-536. ( in Japanese)

(Received January 5, 2012; Accepted January 31, 2012) 